\section{Increased amplification efficiency of microchip-based PCR by dynamic surface passivation}

Xing Jian Lou ${ }^{1}$, Nicholas J. Panaro ${ }^{1}$, Peter Wilding ${ }^{1}$, Paolo Fortina $^{2}$, and Larry J. Kricka ${ }^{1}$

${ }^{1}$ University of Pennsylvania School of Medicine, Philadelphia and ${ }^{2}$ Thomas Jefferson University, Philadelphia, PA, USA

BioTechniques 36:248-252 (February 2004)

Surface passivation is critical for effective PCR using silicon-glass chips. We tested a dynamic polymer-based surface passivation method. Polyethylene glycol 8000 (PEG 8000) or polyvinylpyrrolidone $40(P V P-40)$ applied at $0.75 \%(w / v)$ in the reaction mixture produced significant surface passivation effects using either native or $\mathrm{SiO}_{2}$-precoated silicon-glass chips. PCR amplification was achieved from human genomic DNA as a template as well as from human lymphocytes. The dynamic surface passivation effect of PEG 8000 remained similar under both conditions. Dynamic surface passivation offers a simple and cost-effective method to make microfabricated silicon-glass chips PCR friendly. It can also be used in combination with static passivation (silicon oxide surface layer) to further improve PCR performance using silicon-glass PCR chips.

\section{INTRODUCTION}

The considerable potential of microchip technology is evident from the diverse range of devices and emerging applications $(1,2)$. A popular analytical format couples PCR with sample preparation or product detection (3-7). PCR microchips have been primarily fabricated from glass or glass and silicon, although other materials such as polyimide (8) and polydimethylsiloxane (PDMS) $(9,10)$ have also proved suitable construction materials. However, surface adsorp- tion and large surface area/volume ratio are two factors that complicate the design and construction of PCR microchips. Early work with silicon-glass microchips revealed the problems of adverse surface interactions and led to the development of passivation procedures to render the internal surfaces of microchips PCR friendly (11). Passivation procedures can be classified into two different types: static passivation where the surface is treated

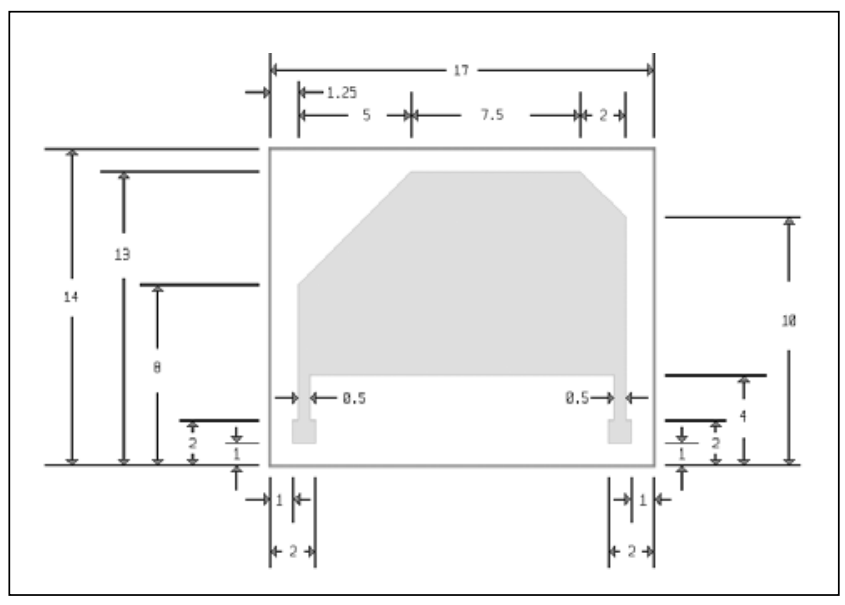

Figure 1. Silicon-glass PCR chip. All structures etched into the silicon are shown in gray. All dimensions are in millimeters. The 1-mm squares serve as the inlet and outlet for the PCR mixture. before performing PCR (6,11-19) and dynamic passivation where passivating agents are introduced into the reaction mixture $(8,13,15,16,20,21)$. While most dynamic coating performed for PCR chips has involved bovine serum albumin (BSA) $(15,16,21,22)$, dynamic coating using polymers polyethylene glycol 8000 (PEG 8000) and polyvinylpyrrolidone (PVP) has also been tested in glass and polyimide chips $(8,13)$ but not in silicon chips. Dynamic passivation using polymers is attractive because polymers are inexpensive, and the coating procedure adds no additional steps into either microchip fabrication or the overall assay procedure. Here we investigate dynamic surface passivation of silicon-glass microchips using various polymers previously shown to be effective with glass and polyimide chips $(8,13)$. In addition, the effectiveness of combining dynamic and static passivation has been evaluated.

\section{MATERIALS AND METHODS}

\section{Silicon Chip Fabrication and Surface Treatment}

Silicon-glass PCR chips (reaction volume: approximately $10 \mu \mathrm{L}$; surface area: approximately $200 \mathrm{~mm}^{2}$ ) (Figure

Figure 2. Effect of polymers on PCR of the human endothelial nitric oxide synthase (eNOS) gene under conventional thermal cycling conditions in GeneAmp reaction tubes. Experiments were run in triplicate or quadruplicate. (A) No polymer; (B) $0.15 \%$ (w/v) poly(ethylene oxide) (gray bar) (molecular weight: 1 million); (C) polyvinyl alcohol type II; (D) polidocanol; (E) polyethylene glycol (PEG) 3350; (F) polyvinylpyrrolidone 40 (PVP-40); (G) Polypep (high viscosity); (H) PEG 8000; (I) 7.5\% PEG 8000 (open bar). Polymer concentration was $0.75 \%$ (w/v) (solid bars), except for poly(ethylene oxide), which was used at $0.15 \%$ (w/v) (gray bar).The product amount in the presence of polymers was normalized to that of the absence of polymer (100\%). The relative amount on the $y$-axis represents the mean of the replicates, and the error bar shows the standard deviation. 
1) were microfabricated at Cornell University Nanotechnology Center (Ithaca, NY, USA) using standard photolithographic procedures as previously described $(11,23)$. Each PCR chip measures $14 \times 17 \mathrm{~mm}$, and all structures are etched into silicon to a depth of $100 \mu \mathrm{m}$. A $2000 \AA$ thick layer of $\mathrm{SiO}_{2}$ was deposited onto some of the chips to produce a PCR friendly passive surface layer using standard deposition techniques. A surface-polished Pyrex ${ }^{\circledR}$ glass cover was then anodically bonded to the etched silicon with or without $\mathrm{SiO}_{2}$ coating to produce the microreaction chamber for PCR $(5,11,23)$.

\section{Isolation of Human Lymphocytes}

Blood from healthy volunteers was drawn into tubes that were precoated with EDTA. Lymphocytes were isolated using Red Blood Cell Lysis Buffer purchased from Roche Applied Science (Indianapolis, IN, USA). The isolated lymphocytes were used immediately.

\section{Polymers}

The polymers tested in this study were from Sigma (St. Louis, MO, USA), unless otherwise indicated, and included PEG 8000 (Promega, Madison, WI, USA), PEG 3500, PVP-40, poly(ethylene oxide) (molecular weight: 1 million) (Aldrich, Milwaukee, WI, USA), polyvinyl alcohol type II, polidocanol, and Polypep ${ }^{\circledR}$ (High viscosity).

\section{PCR Using Human Genomic DNA as Template}

PCR amplification using siliconglass chips was performed as previously described $(5,11,23)$, with minor modifications. Microfabricated siliconglass chips were filled with $10 \mu \mathrm{L}$ PCR mixture containing $1.6 \mathrm{mM}$ dNTP, 1.75 $\mathrm{mM} \mathrm{MgCl}_{2}, 0.5 \mathrm{U}$ AmpliTaq Gold ${ }^{\circledR}$ (Applied Biosystems, Foster City, CA, USA), $0.1 \mu \mathrm{M}$ each primer, and $0.2 \mathrm{ng}$ human genomic DNA (BD Biosciences Clontech, Palo Alto, CA, USA). Primers for human endothelial nitric oxide synthase (eNOS) generating a 379-bp PCR target were forward primer $5^{\prime}$ GTGATGGCGAAGCGAGTGAAG-3' and reverse primer $5^{\prime}$-GACACCACGTCATACTCATCC-3'. In some experiments, a final concentration of $0.75 \%$ PEG 8000, PVP-40, or polyvinyl alcohol type II was also added into the PCR mixture to test the effect of the PCR amplification of the dynamic coating in silicon-glass chips. The chip thermal cycler (custom-made; Custom Medical Research Equipment, Glendora, NJ, USA) holds two chips, thus allowing for the simultaneous comparison of two different tests. The reaction mixture was initially heated for $10 \mathrm{~min}$ at $95^{\circ}$, followed by 45 cycles of $94^{\circ}$ for $1 \mathrm{~min}$, $65^{\circ}$ for $1 \mathrm{~min}, 72^{\circ}$ for $1 \mathrm{~min}$, and finally heated at $72^{\circ} \mathrm{C}$ for $5 \mathrm{~min}$. All of the silicon-glass chip PCR amplifications were run in parallel in GeneAmp ${ }^{\circledR}$ reaction tubes (Applied Biosystems) using a

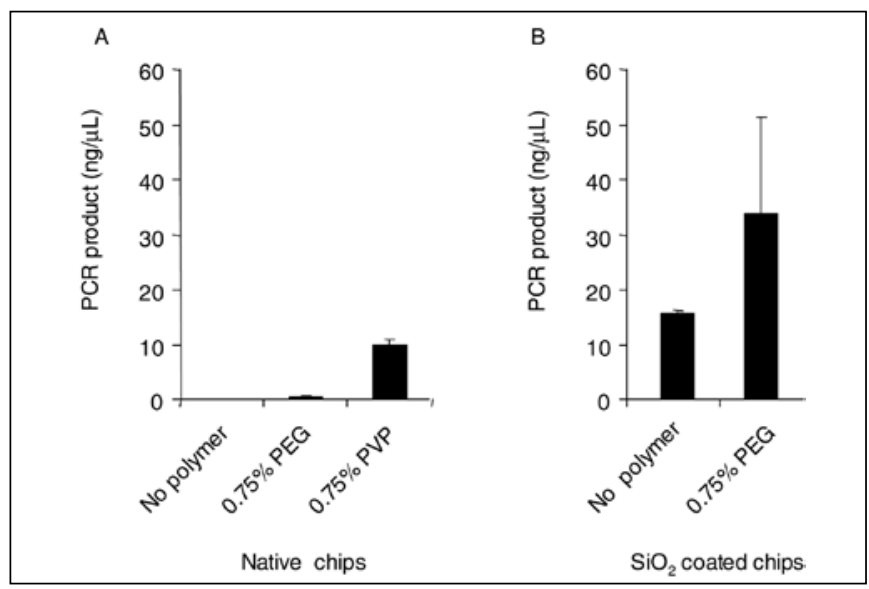

Figure 3. Dynamic surface passivation using polymers in the PCR mixture in (A) native silicon-glass chips and (B) $\mathrm{SiO}_{2}$-coated silicon-glass chips. Each of the experiments was performed in duplicate or triplicate. The product amount on the $y$-axis represents the mean of the replicates, and the error bar shows the standard deviation. PEG, polyethylene glycol. 
conventional thermal cycler (24). For experiments testing the inhibitory effects of polymers on PCR amplification, $0 \%-15 \%$ of the polymers described above were added into the PCR mixture and run in a conventional thermal cycler (GeneAmp 2400; Applied Biosystems).

\section{PCR Amplification Directly From Human Lymphocytes}

The human eNOS fragment was amplified in $10 \mu \mathrm{L}$ silicon-glass chips from 250 cells $/ \mu$ lymphocytes isolated from the whole blood of healthy donors. The primer sequence information and the thermal cycling conditions were as described above.

\section{Capillary Electrophoresis}

The amplified products were detected and quantified using a DNA 1000 or DNA 500 LabChip ${ }^{\circledR}$ Kit (Caliper Technologies, Mountain View, CA, USA) and Agilent 2001 analyzer (Agilent Technologies, Palo Alto, CA, USA) (24).

\section{RESULTS AND DISCUSSION}

In preparation for use in silicon-glass PCR chips (Figure 1), the polymers chosen for the dynamic passivation study were prescreened in a GeneAmp reaction tube-based PCR amplification to eliminate any polymers that inhibited PCR. Seven polymers [PEG 8000, PEG 3500, PVP-40, poly(ethylene oxide) (molecular weight: 1 million), polyvinyl alcohol type II, polidocanol, and Polypep (high viscosity)] at a final concentration of $0.75 \%(\mathrm{w} / \mathrm{v})$ in the PCR mixture [except for poly(ethylene oxide), which was used at a final concentration of $0.15 \%(\mathrm{w} / \mathrm{v})$ ] were screened, and the results are shown in Figure 2. Only polidocanol showed an inhibitory effect (approximately 80\%); the remaining six polymers had no significant effect on the efficiency of PCR. Among these noninhibitory polymers, PEG is well-known to reduce the adsorption of biomolecules to surfaces, and the effect is dependent on both the molecular weight and concentration of the polymer $(25,26)$. We performed a dose response study of the inhibition of PEG 8000 (an intermediate molecular weight PEG) on PCR to determine the maximum non- inhibitory PEG 8000 concentration for surface passivation. The inhibition was initially observed at a final concentration in the PCR mixture of $1.5 \%(\mathrm{w} / \mathrm{v})$ and greater (data not shown), and approximately 50\% inhibition was reached at $7.5 \%(\mathrm{w} / \mathrm{v})$ (Figure 2, open bar). A final concentration of $0.75 \%$ PEG in the PCR mixture was therefore chosen to test the dynamic surface passivation effect of this polymer on silicon-glass chips. As expected, no product was detected for PCR performed in native silicon-glass chips in the absence of polymer (Figure 3A). However, products were detected in PCR performed in native silicon-glass chips in the presence of $0.75 \%$ PEG 8000 . These results indicated that dynamic passivation using PEG is effective and that the success of PCR using silicon-glass chips is dependent on surface passivation, which is in accordance with our previous findings $(11,23)$. Furthermore, the addition of PVP at $0.75 \%$ provided a better surface passivation than PEG 8000 (Figure 3A).

We have previously developed a silicon-glass chip for integrated DNA amplification, in which the inner silicon surface of the chip is coated with a layer of $\mathrm{SiO}_{2}(5,11,23)$. To test the additive effect of thermal coating with $\mathrm{SiO}_{2}$ and dynamic coating with polymers, we compared PCR in $\mathrm{SiO}_{2}$-coated siliconglass chips in the presence and absence of $0.75 \%$ PEG 8000 (Figure 3B) using human genomic DNA as template. The presence of PEG 8000 in the PCR mixture increased the efficiency of the amplification. A similar experiment using isolated human lymphocytes rather than genomic DNA revealed that the addition of $0.75 \%$ PEG 8000 to the PCR mixture significantly increased the efficiency of the amplification (data not shown).

In conclusion, we have shown that dynamic coating with polymers allowed PCR amplification to be performed using native silicon-glass chips and that the combination of dynamic coating with polymers and static coating with thermal oxide on the silicon surface enhanced the PCR amplification more than static coating alone. These results indicate that silicon surfaces can be effectively passivated using dynamic coating with polymers. Any inhibition due to the glass surface is also reduced in this process, in accordance with previous work on the use of polymers to passivate glass sur- faces (13). Therefore, dynamic coating with polymers potentially provides an easy and inexpensive approach for PCR using untreated silicon-glass chips. The chips used in this study had a surface area to volume ratio approximately 13 -fold greater than a conventional MicroAmp ${ }^{\circledR}$ reaction tube (Applied Biosystems). It is possible that smaller chips with higher surface area to volume ratios may behave differently and require the reoptimization of the passivation procedure.

\section{ACKNOWLEDGEMENTS}

This work was supported by a grant from the National Cancer Institute (no. NCI RO1-CA 78848-04).

\section{REFERENCES}

1.Cheng, J. and L.J. Kricka. 2001. Biochip Technology. Harwood Academic Publishers, Philadelphia, PA.

2.Kricka, L.J. and P. Fortina. 2002. Microchips: an all-language literature survey including books and patents. Clin. Chem. 48:1620-1622.

3.Belgrader, P., W. Benett, D. Hadley, J. Richards, P. Stratton, R. Mariella, Jr., and F. Milanovich. 1999. PCR detection of bacteria in seven minutes. Science 284:449-450.

4.Burns, M.A., B.N. Johnson, S.N. Brahmasandra, K. Handique, J.R. Webster, M. Krishnan, T.S. Sammarco, P.M. Man, et al. 1998. An integrated nanoliter DNA analysis device. Science 282:484-487.

5.Wilding, P., L.J. Kricka, J. Cheng, G. Hvichia, M.A. Shoffner, and P. Fortina. 1998. Integrated cell isolation and polymerase chain reaction analysis using silicon microfilter chambers. Anal. Biochem. 257:95-100.

6.Woolley, A.T., D. Hadley, P. Landre, A.J. deMello, R.A. Mathies, and M.A. Northrup. 1996. Functional integration of PCR amplification and capillary electrophoresis in a microfabricated DNA analysis device. Anal. Chem. 68:40814086.

7.Yuen, P.K., L.J. Kricka, P. Fortina, N.J. Panaro, T. Sakazume, and P. Wilding. 2001. Microchip module for blood sample preparation and nucleic acid amplification reactions. Genome Res. 11:405-412.

8.Giordano, B.C., J. Ferrance, S. Swedberg, A.F. Huhmer, and J.P. Landers. 2001. Polymerase chain reaction in polymeric microchips: DNA amplification in less than 240 seconds. Anal. Biochem. 291:124-132.

9.Hong, J.W., T. Fujii, M. Seki, T. Yamamoto, and I. Endo. 2001. Integration of gene amplification and capillary gel electrophoresis on a polydimethylsiloxane-glass hybrid microchip. Electrophoresis 22:328-333.

10.Martin, R.S., A.J. Gawron, and S.M. Lunte. 2000. Dual-electrode electrochemical detection for poly(dimethylsiloxane)-fabricated capillary electrophoresis microchips. Anal. Chem. 72: 


\section{SHORT TECHNICAL REPORTS}

3196-3202.

11.Shoffner, M.A., J. Cheng, G.E. Hvichia, L.J. Kricka, and P. Wilding. 1996. Chip PCR. I. Surface passivation of microfabricated silicon-glass chips for PCR. Nucleic Acids Res. 24:375-379.

12.Anderson, R.C., X. Su, G.J. Bogdan, and J. Fenton. 2000. A miniature integrated device for automated multistep genetic assays. Nucleic Acids Res. 28:E60.

13.Giordano, B.C., E.R. Copeland, and J.P. Landers. 2001. Towards dynamic coating of glass microchip chambers for amplifying DNA via the polymerase chain reaction. Electrophoresis 22:334-340.

14.Hong, J.W., T. Fujii, M. Seki, T. Yamamoto, and I. Endo. 2000. PDMS (polydimethylsiloxane)-glass hybrid microchip for gene amplification, p. 407-410. In A. Dittmar and D. Beebe (Eds.), 1st Annual International IEEE-EMBS Special Topic Conference on Microtechnologies in Medicine and Biology. Proceedings. IEEE. Piscataway, NJ.

15.Khandurina, J., T.E. McKnight, S.C. Jacobson, L.C. Waters, R.S. Foote, and J.M. Ramsey. 2000. Integrated system for rapid PCRbased DNA analysis in microfluidic devices. Anal. Chem. 72:2995-3000.

16.Lagally, E.T., I. Medintz, and R.A. Mathies. 2001. Single-molecule DNA amplification and analysis in an integrated microfluidic device.
Anal. Chem. 73:565-570.

17.Northrup, M.A., B. Benett, D. Hadley, P. Landre, S. Lehew, J. Richards, and P. Stratton. 1998. A miniature analytical instrument for nucleic acids based on micromachined silicon reaction chambers. Anal. Chem. 70:918-922.

18.Poser, S., T. Schulz, U. Dillner, V. Baier, J.M. Kohler, D. Schimkat, G. Mayer, and A. Siebert. 1997. Chips elements for fast thermocycling. Sens. Actuators A 62:672-675.

19.Taylor, T.B., E.S. Winn-Deen, E. Picozza, T.M. Woudenberg, and M. Albin. 1997. Optimization of the performance of the polymerase chain reaction in silicon-based microstructures. Nucleic Acids Res. 25:3164-3168.

20.Nagai, H., Y. Murakami, Y. Morita, K. Yokoyama, and E. Tamiya. 2001. Development of a microchamber array for picoliter PCR. Anal. Chem. 73:1043-1047.

21.Trau, D., T.M. Lee, A.I. Lao, R. Lenigk, I.M. Hsing, N.Y. Ip, M.C. Carles, and N.J. Sucher. 2002. Genotyping on a complementary metal oxide semiconductor silicon polymerase chain reaction chip with integrated DNA microarray. Anal. Chem. 74:3168-3173.

22.Lee, T.M., I.M. Hsing, A.I. Lao, and M.C. Carles. 2000. A miniaturized DNA amplifier: its application in traditional Chinese medicine. Anal. Chem. 72:4242-4247.

23.Cheng, J., M.A. Shoffner, G.E. Hvichia, L.J.
Kricka, and P. Wilding. 1996. Chip PCR. II Investigation of different PCR amplification systems in microfabricated silicon-glass chips. Nucleic Acids Res. 24:380-385.

24.Panaro, N.J., P.K. Yuen, T. Sakazume, P. Fortina, L.J. Kricka, and P. Wilding. 2000. Evaluation of DNA fragment sizing and quantification by the Agilent 2100 Bioanalyzer. Clin. Chem. 46: 1851-1853.

25.Kingshott, P., S. McArthur, H. Thissen, D.G. Castner, and H.J. Griesser. 2002. Ultrasensitive probing of the protein resistance of PEG surfaces by secondary ion mass spectrometry. Biomaterials 23:4775-4785

26.Lee, J.H., H.B. Lee, and J.D. Andrade. 1995. Blood compatibility of polyethylene oxide surfaces. Prog. Polym. Sci. 20:1043-1079.

Received 17 November 2003; accepted 10 December 2003.

Address correspondence to Larry J. Kricka, Department of Pathology and Laboratory Medicine, University of Pennsylvania, 3400 Spruce Street, Philadelphia, PA 19104, USA.e-mail: kricka@mail.med.upenn.edu 